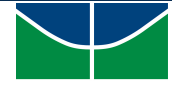

\title{
UnB
}

\section{Development of a Low Cost Space Telescope for Earth Remote Sensing from a $12 \mathrm{U}$ CubeSat}

Helcio Vieira Junior* and Manuel N. D. Barcelos Junior

helciovj@unb.br

Oct 9th, 2018

University of Brasilia, Campus Universitario Darcy Ribeiro, Brasilia, Brazil 


\section{Introduction}

\section{Introduction}

The Project

Why Polarization?

Preliminary Optical Project

Radiometric

Considerations

Preliminary Mechanical Project

Next Steps

Conclusion
The purpose of this work is to develop a low cost space telescope for Earth remote sensing that could be housed in a $12 \mathrm{U}$ CubeSat with a GSD of 25 meters at LWIR. It will be used the Three Mirror Anastigmatic concept and Commercial Off-The-Shelf components whenever it is possible.
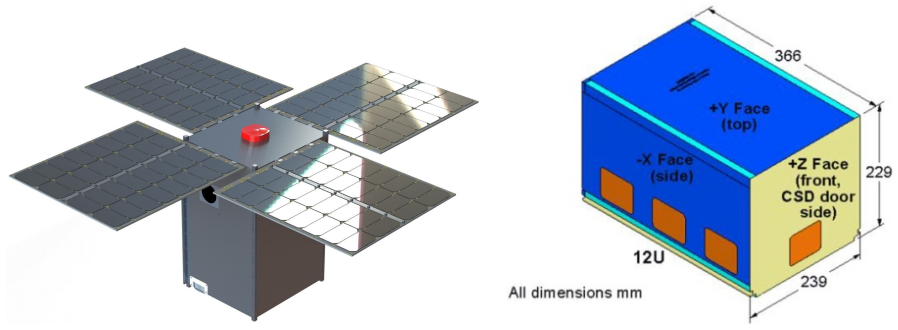

Source: Planetary Systems Corporation

http://www.planetarysystemscorp.com/wp-content/uploads/2018/08/2002367F-Payload-Spec-for-3U-6U12U.pdf

Development of a Low Cost Space Telescope for Earth Remote Sensing from a $12 \mathrm{U}$ CubeSat 


\section{Introduction}

\section{Agenda}

\section{Introduction}

The Project

Why Polarization?

Preliminary Optical Project

Radiometric

Considerations

Preliminary Mechanical Project

Next Steps

Conclusion
- Introduction

- The Project

- Why Polarization?

- Preliminary Optical Project

- Radiometric Considerations

- Preliminary Mechanical Project

- Next Steps

- Conclusion 


\section{The Project}

Missions I

\section{Introduction}

The Project

Why Polarization?

Preliminary Optical Project

Radiometric

Considerations

Preliminary Mechanical Project

Next Steps

Conclusion
- The telescope main mission is the oil spill detection, mainly in ocean environment. Beyond the obvious functionality of this main mission, the oil spill detection can be very useful to detect crashed aircrafts in the ocean (as the accident of the Air France 447, flying between Rio de Janeiro, Brazil, and Paris, France, which crashed at May 31, 2009).

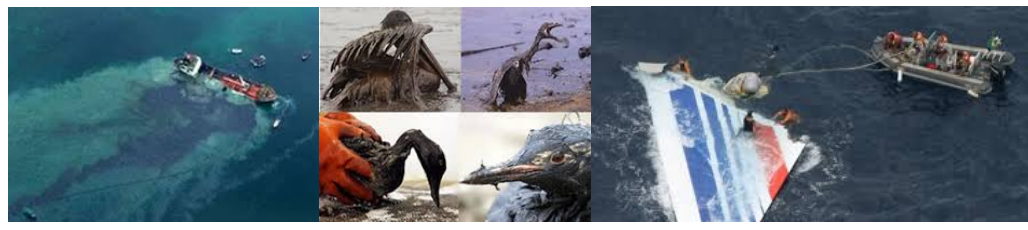

Development of a Low Cost Space Telescope for Earth Remote Sensing from a 12 U CubeSat 
Introduction

The Project

Why Polarization?

Preliminary Optical Project

Radiometric

Considerations

Preliminary Mechanical Project

Next Steps

Conclusion
As secondary missions, this telescope can be used to map deforestation, finding lost ships in the ocean and help the drug smuggling by finding camouflaged man-made objects.

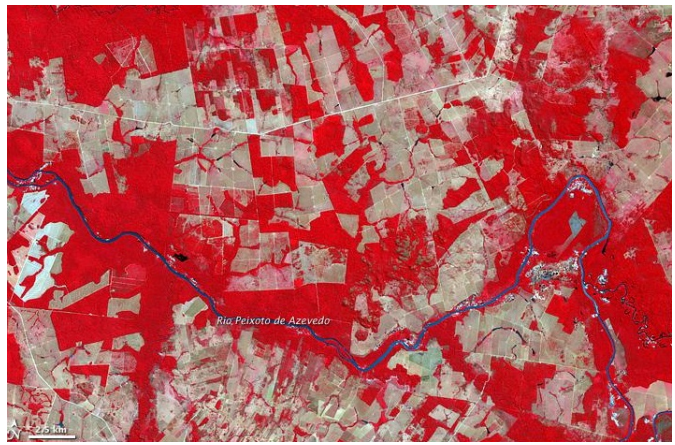

- In order to achieve these goals, the telescope will extract polarization information from the target. 


\section{The Project}

Current Status

\section{Introduction}

The Project

Why Polarization?

Preliminary Optical Project

Radiometric

Considerations

Preliminary Mechanical Project

\section{Next Steps}

Conclusion
- The current stage of this work consists in preliminary optical and mechanical projects in which the mirrors follow ITAR regulation.

- The ITAR regulation constrains the maximum aperture stop of the optics allowable to be exported to be smaller than $50 \mathrm{~cm}$. 


\section{Introduction}

The Project

Why Polarization?

Preliminary Optical Project

Radiometric

Considerations

Preliminary Mechanical Project

Next Steps

Conclusion

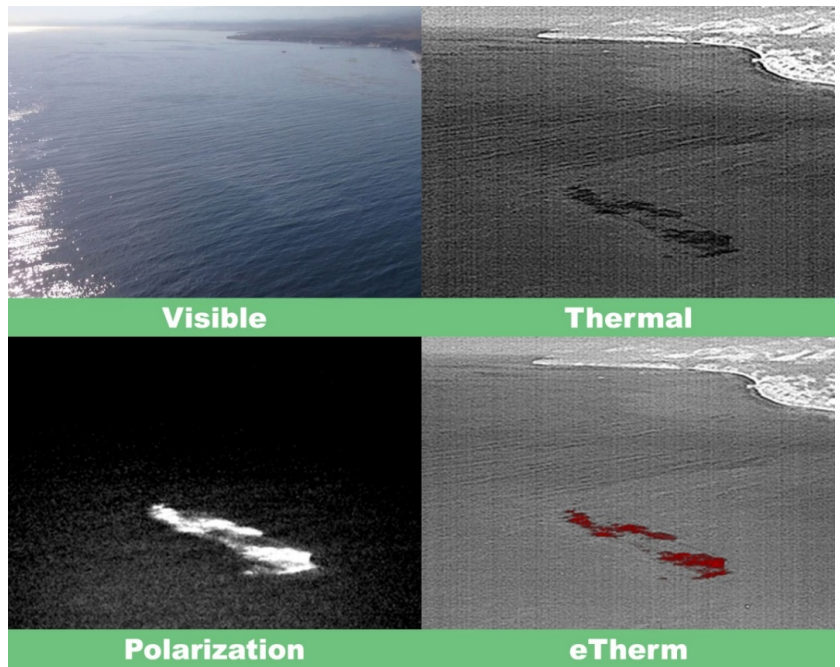

Source: Polaris

http://www.polarissensor.com/applications/water-detection/oil-and-diesel

Development of a Low Cost Space Telescope for Earth Remote Sensing from a 12U CubeSat 


\section{Introduction}

The Project Why Polarization? Preliminary Optical Project Radiometric Considerations Preliminary Mechanical Project

Next Steps

Conclusion
- The preliminary optical project took as hypotheses a FPA with pixel pitch of 17 microns, a wavelengh range from 7.5 to 13.5 microns, a flight altitude of $450 \mathrm{~km}$, an aperture stop of $18.75 \mathrm{~cm}$ and a focal lenght of $306 \mathrm{~mm}$. These data lead to a GSD (ground sampling distance) of $25 \mathrm{~m}$ and a GRD* (ground resolution distance) of $30.74 \mathrm{~m}$.

- The preliminary optical project indicates that the telescope optical performance has MTF greater than $45 \%$ at Nyquist frequency, native GSD of 25 meters and that the telescope is diffraction limited (wavefront error of 0.012 wavelengths and Strehl ratio of $99.38 \%$ ).

* The GRD corresponds to the Rayleigh resolution criterion. 


\section{The Project}

\section{Preliminary Optical Project II}

\section{Introduction}

The Project

Why Polarization?

Preliminary Optical Project

Radiometric

Considerations

Preliminary Mechanical Project

Next Steps

Conclusion

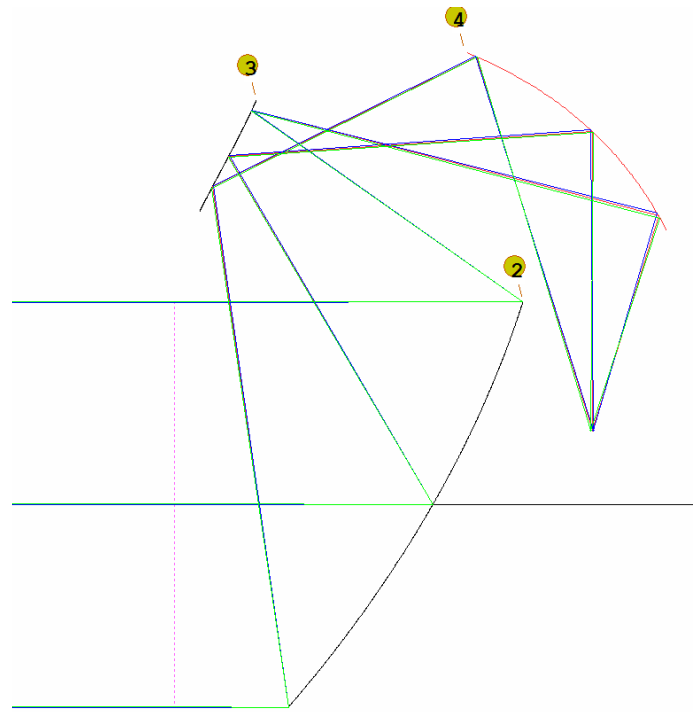

Development of a Low Cost Space Telescope for Earth Remote Sensing from a 12U CubeSat 


\section{The Project}

\section{Preliminary Optical Project III}

\section{Introduction}

The Project

Why Polarization?

Preliminary Optical Project

Radiometric

Considerations

Preliminary Mechanical Project

Next Steps

Conclusion

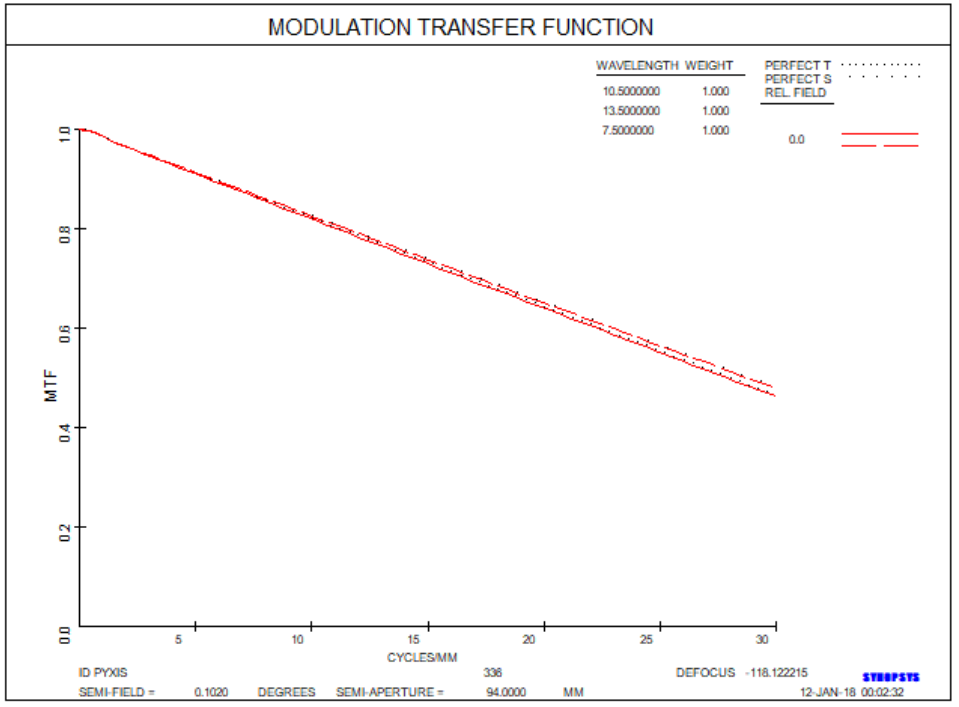

Development of a Low Cost Space Telescope for Earth Remote Sensing from a $12 \mathrm{U}$ CubeSat 


\section{The Project}

\section{Introduction}

The Project

Why Polarization?

Preliminary Optical Project

Radiometric

Considerations

Preliminary Mechanical Project

Next Steps

Conclusion
- Redjimi et al (2018) state that the Noise Equivalent Temperature Difference (NETD) is directly proportional to the square of the F-number $(f / \#)$ and is inversely proportional to the incident radiation.

- Kohin and Butler (2004) state that there is a NETD $/ \tau^{*}$ proportionality relationship and that it is accurate since the NETD is limited by $1 / f$ noise.

* $\tau$ (Thermal Response Time): physical time a bolometer needs to heat up and give an electrical output that equals or represents the input.

Redjimi, A., Knezevic, D., Savic, K., Jovanovic, N., Simovic, M., and Vasiljevic, D., "Noise Equivalent Temperature Difference Model for Thermal Imagers, Calculation and Analysis." Unpublished. http: //www . vti.mod.gov.rs/ntp/rad2014/2-2014/6/6.pdf. (Accessed: January 29, 2018).

Kohin, M. and Butler, N., "Performance limits of uncooled vox microbolometer focal plane arrays," in [Proc. of SPIE], 5406 (2004). 


\section{The Project}

\section{Introduction}

The Project

Why Polarization?

Preliminary Optical Project

Radiometric

Considerations

Preliminary Mechanical Project

Next Steps

- We assume a commercial microbolometer FPA (thermal response time of $14 \mathrm{~ms}$ and NETD of $40 \mathrm{mK}$ at $f / \#=1.0)$ and the optics described at PRELIMINARY OPTICAL PROJECT with $f / \#=1.632$.

- Given the NETD $/ \tau$ proportionality relationship, it is possible to achieve, with the same technology of this commercial microbolometer, a FPA with thermal response time of $1.17 \mathrm{~ms}$ and NETD of $480.0 \mathrm{mK}$ $(14.0 \times 40.0=1.17 \times 480.0)$.

- The optics make the NETD to be $1278.44 \mathrm{mK}$. Assuming the polarization filter will divide the signal into 4 equal parts, then NETD $=5113.77 \mathrm{mK}$.

- Finally, with a TDI of 32 stages, we will have a NETD of $0.90 \mathrm{~K}$. 


\section{The Project}

Radiometric Considerations III

Introduction

The Project

Why Polarization?

Preliminary Optical Project

Radiometric

Considerations

Preliminary Mechanical Project

Next Steps

Conclusion
In this fashion, we propose a FPA with fast thermal response time $(3 \times 1.17 \mathrm{~ms}=3.5 \mathrm{~ms}=25 \mathrm{~m} \mathrm{GSD})$ and 32 stages of TDI, where each block of same polarization has 640 columns by 8 lines.

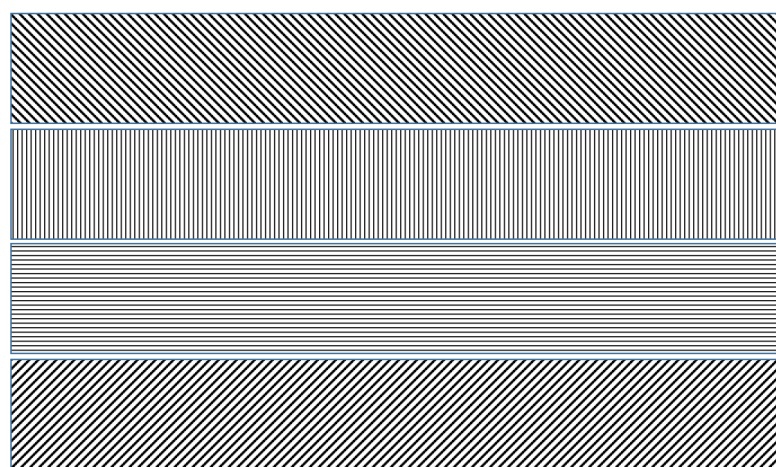

Development of a Low Cost Space Telescope for Earth Remote Sensing from a 12U CubeSat 


\section{The Project}

\section{Introduction}

The Project Why Polarization? Preliminary Optical Project Radiometric Considerations Preliminary Mechanical Project

Next Steps
- We opted to use aerospace qualified aluminum (Al6061-T6) as substract to both mirrors and structure.

- The reasons that drove this decision were the same ones listed by Scheiding et al (2010): "Al6061-T6, which is diamond turnable but also offers distinguished optical quality for IR-optics, especially if fine grain sized aluminum alloy like RSA-6061 is used".

Scheiding, S., Damm, C., Holota, W., Peschel, T., Gebhardt, A., Risse, S., and Tnnermann, A., "A ultraprecisely manufactured mirror assemblies with well defined reference structures," in [Proc. of SPIE], 7739, D1-D10 (2010). 


\section{The Project}

Preliminary Mechanical Project II

\section{Introduction}

The Project

Why Polarization?

Preliminary Optical Project

Radiometric

Considerations

Preliminary Mechanical Project

Next Steps

Conclusion
The preliminary mechanical project, added by the light rays, is shown bellow, where the mirrors are painted in dark gray, the light rays in blue and the structure in light gray.

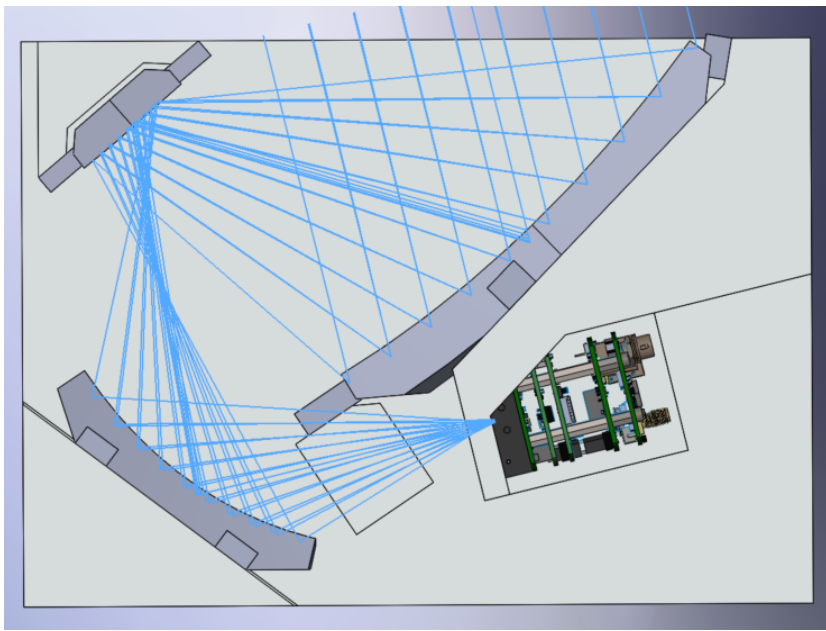

Development of a Low Cost Space Telescope for Earth Remote Sensing from a $12 \mathrm{U}$ CubeSat 


\section{The Project}

Preliminary Mechanical Project III

\section{Introduction}

The Project

Why Polarization?

Preliminary Optical Project

Radiometric

Considerations

Preliminary Mechanical Project

Next Steps

Conclusion
It was done a study on the mechanical project through finite element method. This study showed the maximum deflection $\delta$ caused by gravity is smaller than 74 nanometers.

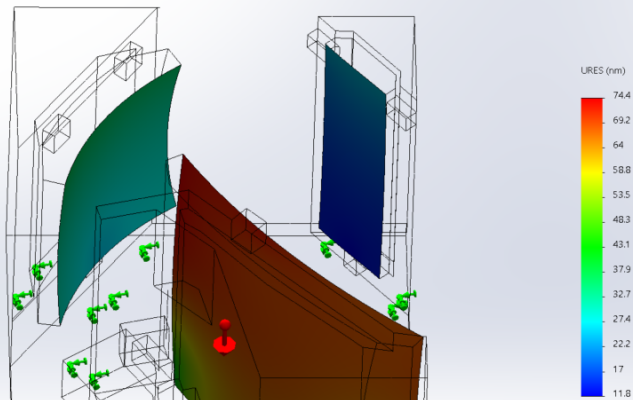

Development of a Low Cost Space Telescope for Earth Remote Sensing from a $12 \mathrm{U}$ CubeSat 


\section{The Project}

Preliminary Mechanical Project / Perspective Views I

Introduction

The Project

Why Polarization?

Preliminary Optical Project

Radiometric

Considerations

Preliminary Mechanical Project

Next Steps

Conclusion

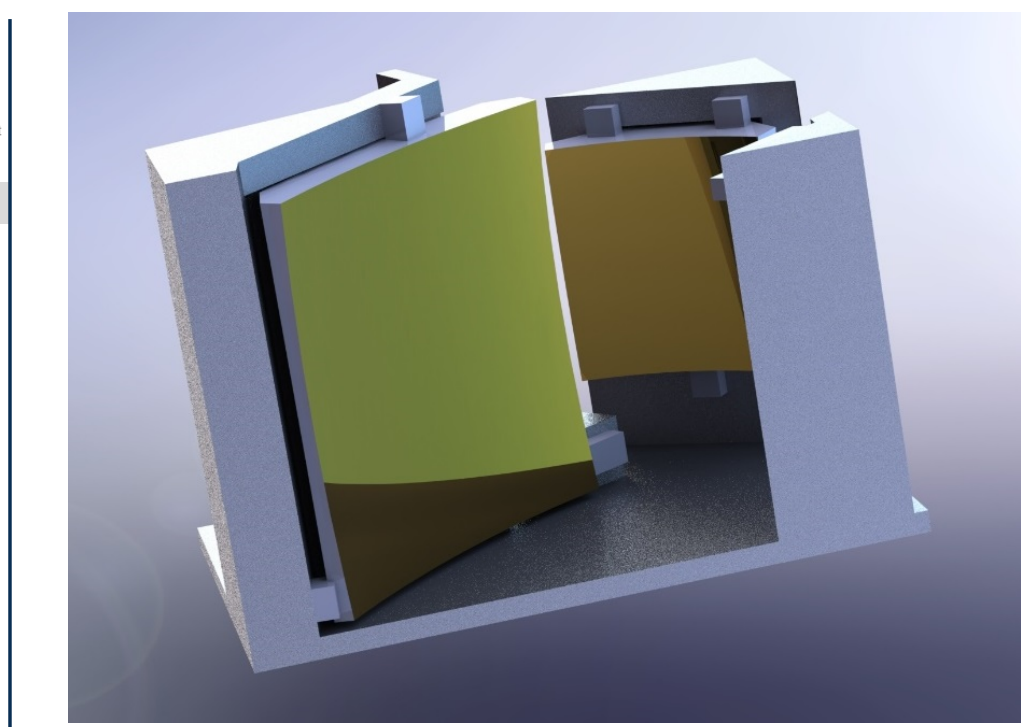

Development of a Low Cost Space Telescope for Earth Remote Sensing from a 12 U CubeSat 


\section{The Project}

Preliminary Mechanical Project / Perspective Views II

\section{Introduction}

The Project

Why Polarization?

Preliminary Optical Project

Radiometric

Considerations

Preliminary Mechanical Project

Next Steps

Conclusion

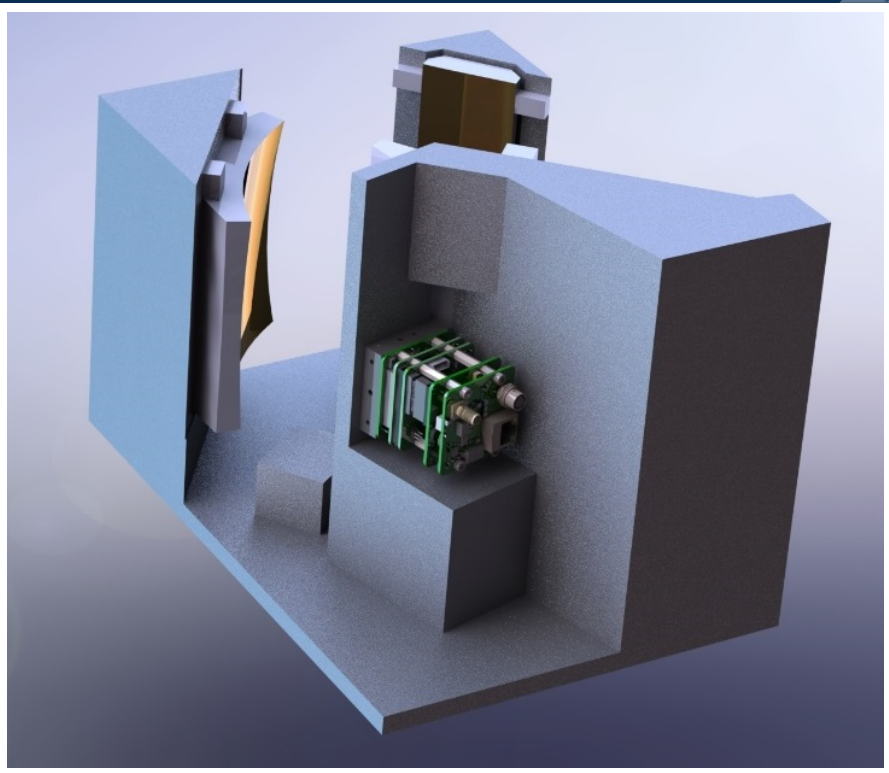

Development of a Low Cost Space Telescope for Earth Remote Sensing from a 12U CubeSat 


\section{The Project}

Preliminary Mechanical Project / Perspective Views III

Introduction

The Project

Why Polarization?

Preliminary Optical Project

Radiometric

Considerations

Preliminary Mechanical Project

Next Steps

Conclusion

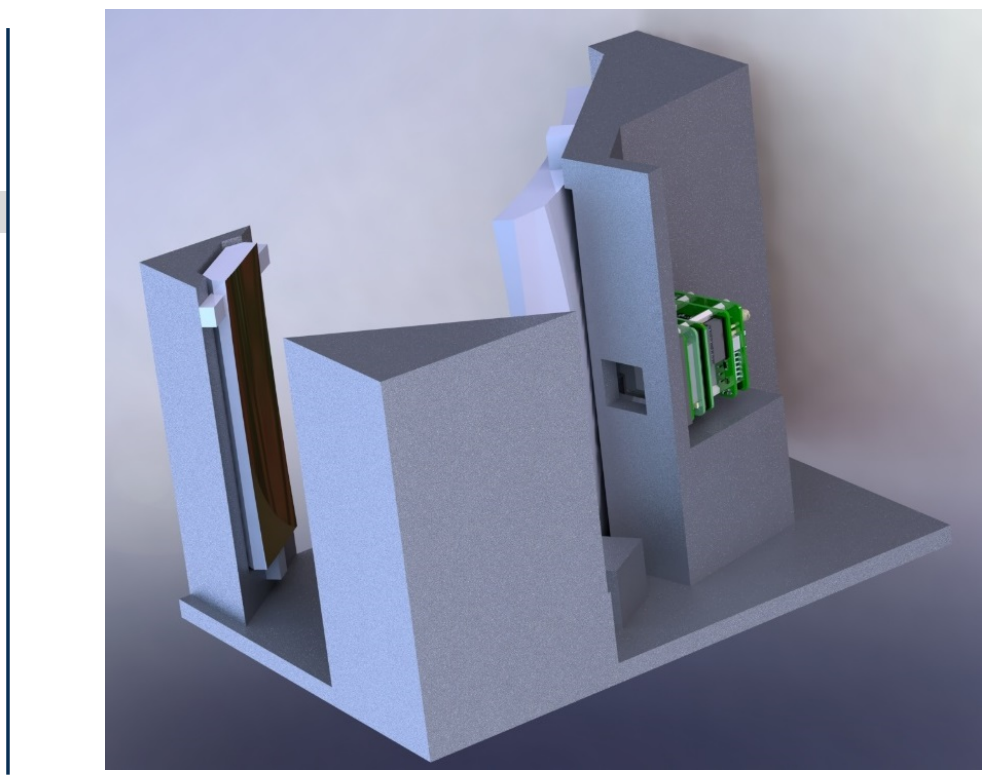

Development of a Low Cost Space Telescope for Earth Remote Sensing from a 12U CubeSat 


\section{Next Steps I}

\section{Introduction}

The Project

Why Polarization?

Preliminary Optical Project

Radiometric

Considerations

Preliminary Mechanical Project

Next Steps

Conclusion
- Frozen the FPA to be utilized: this step is essential to allow the next one (radiometric analysys);

- Do the radiometric analysis: this is the most critical step. The reason is that it could not exist a microbolometer FPA with line rate and response time fast enough to allow the desired GSD with an acceptable NETD. If this will be the case, our alternative would be increase the pixel pitch and also the GSD;

- Do the sensitivity analysis on the optical project: it will allow the procurement of the mirrors; 


\section{Next Steps II}

\section{Introduction}

The Project

Why Polarization?

Preliminary Optical Project

Radiometric

Considerations

Preliminary Mechanical Project

Next Steps

Conclusion
- Finish the static analysis on the mechanical project;

- Do the frequency response analysis on the mechanical project: this analysis will show if there will be restrictions on what type of launchers (rockets) could be used to orbit this sensor;

- Do the thermal analysis on both optical and mechanical projects: it will show how many thermostat and heaters will be necessary to maintain the telescope without thermal gradients. It will also furnish the estimate of power consumption of the sensor. 


\section{Conclusion I}

\section{Introduction}

The Project

Why Polarization?

Preliminary Optical Project

Radiometric

Considerations

Preliminary Mechanical Project

\section{Next Steps}

Conclusion
- It could be seen that the preliminary optical project indicated that the telescope optical performance has Modulation Transfer Function greater than $45 \%$ at Nyquist frequency, native GSD of 25 meters and that the telescope is diffraction limited (wavefront error of 0.012 wavelengths and Strehl ratio of $99.38 \%$ ).

- The preliminary mechanical project indicated that the maximum deflection caused by gravity induces to a despicable error (smaller than one over one hundred and forty) when compared to the mean wavelength of operation.

- The preliminary radiometric analyses indicated that the telescope has a NETD of $0.90 \mathrm{~K}$. 


\section{Conclusion II}

\section{Introduction}

The Project

Why Polarization?

Preliminary Optical Project

Radiometric

Considerations

Preliminary Mechanical Project

\section{Next Steps}

Conclusion
We are still in the very beginning of this project, but the results we have so far strongly support our believe that the fulfillment of our goals is feasible.

\section{Acknowledgments}

We would like to thank the Fundacao de Apoio a Pesquisa do Distrito Federal (FAP-DF) for its financial support. 


\section{Thank You.}

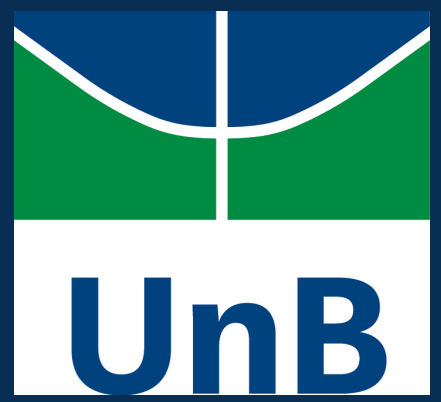

Helcio Vieira Junior* and Manuel N. D. Barcelos Junior 


\section{Back Up Slides}

Radiometric Considerations I

\section{Introduction}

The Project

Why Polarization?

Preliminary Optical Project

Radiometric

Considerations

Preliminary Mechanical Project

\section{Next Steps}

Conclusion

- We assume a commercial microbolometer FPA (thermal response time of $14 \mathrm{~ms}$ and NETD of $40 \mathrm{mK}$ at $f / \#=1.0)$ and the optics described at PRELIMINARY OPTICAL PROJECT with $f / \#=f / D=1.632$.

- We found a commercial microbolometer FPA (thermal response time of $12 \mathrm{~ms}$, frame rate of $120 \mathrm{~Hz}$ and NETD of $50 \mathrm{mK}$ at $f / \#=1.0$ ) and the optics described at PRELIMINARY OPTICAL PROJECT with $f / \#=1.262$. 


\section{Back Up Slides}

\section{Introduction}

The Project

Why Polarization?

Preliminary Optical Projec

Radiometric

Considerations

Preliminary Mechanical Project

Next Steps

Conclusion
- The preliminary optical project took as hypotheses a FPA with pixel pitch of 17 microns, a wavelengh range from 7.5 to 13.5 microns, a flight altitude of $450 \mathrm{~km}$, an aperture stop of $18.75 \mathrm{~cm}$ and a focal lenght of $306 \mathrm{~mm}$. These data lead to a GSD (ground sampling distance) of $25 \mathrm{~m}$ and a GRD (ground resolution distance) of $30.74 \mathrm{~m}$.

- The preliminary optical project took as hypotheses a FPA with pixel pitch of 17 microns, a wavelengh range from 7.5 to 13.5 microns, a flight altitude of $450 \mathrm{~km}$, an aperture stop of $10.1 \mathrm{~cm}$ and a focal lenght of $127.5 \mathrm{~mm}$. These data lead to a GSD (ground sampling distance) of $60.0 \mathrm{~m}$ and a GRD (ground resolution distance) of 59.79 $\mathrm{m}$. 


\section{Introduction}

The Project

Why Polarization?

Preliminary Optical Project

Radiometric

Considerations

Preliminary Mechanical Project

\section{Next Steps}

Conclusion
- The optics make the NETD to be $1278.44 \mathrm{mK}$. Assuming the polarization filter will divide the signal into 4 equal parts, then NETD $=5113.77 \mathrm{mK}$. Finally, with a TDI of 32 stages, we will have a NETD of $0.900 \mathrm{~K}$.

n The optics make the NETD to be $79.63 \mathrm{mK}$. Assuming the polarization filter will divide the signal into 4 equal parts, then NETD $=318.53 \mathrm{mK}$. Finally, with a TDI of 32 stages, we will have a NETD of $0.056 \mathrm{~K}$. 